\title{
An Early Risk Warning Model for Electronic Financial Crime Based on Big Data
}

\author{
Jianying Xiong \\ Security Management Department of Jiangxi Police College \\ Jiangxi Police Institute \\ Nanchang 330013, China \\ special8212@sohu.com
}

\begin{abstract}
The development of electronic finance has provided rich and convenient financial services for the public, but also caused a lot of economic crime. Based on the electronic financial definition, it introduced the mainly existed form of electronic finance in China. It analyzed some characteristics of the electronic finance, such as non-real name, virtual trade, complexity of fund flow, fragments of transaction information. It further analyzed the types of electronic crime, the risk reason of electronic financial crime. Then it explored a framework of risk early-warning model for electronic financial crime based on big data, and explained the feasibility, construction idea, construction principle, and early warning method of constructing warning model. Electronic financial crime investigation prevention and control is comprehensive and complex system engineering. The big data and other information technology is can be used to construct electronic financial crime risk monitoring and early warning mechanism, and it is conducive to the prevention and control of electronic financial crime.
\end{abstract}

Keywords-electronic finance; electronic financial crime; financial crime prevention and control; early risk warning; big data

\section{INTRODUCTION}

In recent years, with the development of the Internet, big data, cloud computing and other technologies, the traditional financial institutions are reformed, and the electronic financial model is also been constantly innovated. Currently, the third party payment in the Internet, P2P network lending, Internet funds, public financing and other emerging, also shows the rapid rise of the Internet banking industry [1]. the "Internet plus" action is promoted by the State Council, the guidance on actively also clearly pointed out that "to encourage the integration of Internet financial innovation, providing a rich and convenient financial products and services to the public, to better meet the different levels of the real economy financing demand. Electronic finance has the characteristics of cross industry, cross market, cross region. It brings convenience to the public, but also with a lot of risks. For example, the subject of transaction identity verification, the protection of consumer information, and other regulatory issues on financial transactions, which makes the risk of online financial crimes is more subtle, more likely to expand [2]. So the public security departments should strengthen the network of financial crime prevention work, timely tracking the crime types and development.

Thanks to Jiangxi province education department, the science and technology plan project, NO.GJJ151194
The crime of electronic financial involved in a wide range personnel, a high amount of money, the subject of crime is professional, intelligent crime method, strong sense of antidetection, electronic evidence of the crime and other characteristics. The big data and other information technology can be used to construct the electronic financial crime risk monitoring and early warning mechanism. It is conducive to the electronic financial crime prevention and control.

\section{ELECTRONIC FINANCE}

\section{A. Definition of Electronic Finance}

At present, there is no uniform definition of "electronic finance" in the world, and it is generally believed that electronic finance is the behavior of financial services relying on Internet technology and tools. The detailed and authoritative definition of financial stability report is issued by the people's Bank of Chinese "(2014)". The report pointed out that the electronic finance is the combination of the Internet and finance, which is a new financial mode of financing, payment and information intermediary function through the Internet and mobile communication technology. In essence, Internet banking is the use of big data, cloud computing, social networking and search engines and other Internet technology to achieve a new financial intermediation services model." [3].

In our country, the electronic finance is conforms to the current Internet and so on related information technology application development. Especially since 2013, the electronic finance has shown the advantages of low transaction costs, high transaction efficiency. The development of China's electronic financial model has been the continuous reform, the transactions scale has grown rapidly. According to the new financial research center of Tsinghua University, University of Cambridge, University of Sydney School of business on the Internet financial report, the benchmark Asia Pacific region in 2015, the Asia Pacific Network alternative financial market growth rate is $323 \%$, a total of $\$ 102$ billion 800 million. Among them, China network alternative financial market is growing at 4 times with annual rate, reaching a total of $\$ 100$ billion, ranked in the top [4].

\section{B. Electronic Financial Characteristics}

(1) The non-real name of the electronic transaction makes the customer identification difficult. Due to the traditional 
financial transactions, banks and other service departments will require customers to produce relevant identification and transaction evidence, which will provide evidence for the traceability of customer information. However, in the network of financial behavior, the user can register a personal account on the site, and then you can log in online account transfer funds anytime, anywhere, which cannot identify the true identity of the user.

(2) The virtual nature of the electronic transactions make it is difficult to identify suspicious transactions. On the one hand, customers in the network of financial transactions, you can transfer money, and no need to specify the use of funds. It has a higher degree of virtualization. On the other hand, the electronic transaction is not restricted by time and space, a large number of small funds enter in an account or out of an account, or complete the transfer of more money in a short time among multiple accounts. They will have a large number of transactions records, and the transaction is complicated, which make it is difficult to identify suspicious transactions.

(3) It is difficult to track the flow of Internet trading funds, which provides convenience for the money laundering. Transfer of funds in the network environment, the customer is not only does not need to direct contact the financial services institutions, but also not constraint to distance, space and time, especially in the case of cross-border transfer of funds. Even if regulators found financial behavior has a suspicious of money laundering, and it is difficult to track and control of electronic transactions.

(4) The fragmentation of the electronic transaction data makes it difficult to obtain the complete information of the transaction. Customers complete a network of transactions, including the issuing agency, electronic payment institutions, telecommunications operators, receiving agencies, cardholders, merchants and even outsourcing services, etc.. This feature makes the payment process is fragment, the involving information of transactions is segmented. Due to the same user transaction information, identity information is stored in different institutions, so it is difficult to obtain the complete transaction information from relevant departments [5].

\section{Electronic Financial Economic Crime Risk}

Because the network has the features of virtuality, anonymity, coupled with the rapid development of electronic finance, the network information security technology and network technology are all lack of financial supervision. The economic crime electronic financial risks cannot be ignored. At present, the typical types of electronic financial economic crime can be summarized as the following three kinds [6].

(1) Electronic financial fraud: financial fraud by the network can be divided into phishing scams, fake money, and credit card cash fraud. The phishing refers to the Trojans, phishing sites, fraudulent e-mail to lure users deceived, entice users to transfer funds or to cheat the user's bank account password; fake money behavior is mainly criminals use P2P lending platform information audit loopholes, forgery of personal identification information and other relevant credit vouchers for a loan after absconding behavior; credit card cash refers to the use of the electronic transaction false, taking credit card funds [7].

(2) Electronic money laundering criminals. On the one hand, criminals transfer of funds to complete the money laundering in the third party payment platform through false trading in electronics; on the other hand, lend black money through vulnerabilities in P2P lending platform, and money will be transferred out of sight supervision [8].

(3) Network illegal fund-raising: criminals forged credit rating, allowing high profit returns, establish unauthorized financial institutions to finance the public, absorb a lot of money. Because the institutions lack of the necessary risk management mechanism, once the investment fails or the occurrence a run on a bank of a large number of customers, the customer funds cannot be guaranteed. At present, with the rapid development of $\mathrm{P} 2 \mathrm{P}$ lending platform, use $\mathrm{P} 2 \mathrm{P}$ network lending platform for illegal financing is emerging in endlessly. For example, E-rent treasure, large group, is suspected of illegal fund-raising.

\section{EARLY WARNING PLATFORM ANALYSIS OF ELECTRONIC FINANCIAL CRIME RISK}

\section{A. Feasibility Analysis of Risk Warning Platform}

Big data is a technology for massive data mining, analysis, which is mainly based on the network platform. The electronic finance is typical kind of data driven industry. Internet financial enterprises can investigate customer information, customer credit history in-depth through big data technology. Audit user data strictly can effectively prevent the network of money laundering, financial fraud, malicious lending and other financial crimes through customer data mining, build a big data electronic financial crime risk monitoring platform for mining different categories of electronic financial crime characteristics, design the advanced risk assessment control system can improve the prediction model of electronic finance, reduce the financial risk of default behavior, to provide security for the customer[9].

\section{B. Ideas to Design Risk Warning Platform}

At present, China is planning to build the national level of social credit system based on government, business, and social, judicial. Plan to achieve a larger share of resources at the end of 2017, integration including the financial, industrial and commercial, tax payment, social security contributions, traffic violations and other information. It will use big data to establish personal credit for each citizen in the future; each citizen will have a unified social credit code. In the process of electronic financial risk assessment, in addition to the acquisition of personal credit information, but also through the electronic of the third party credit rating agencies, such as sesame credit, provide payment records and other quantitative dimensions of personal credit, repayment of users. At the same time, the financial business in the network also saves the user massive transaction data, customer credit information, transaction information, and other information in and out of funds. The use of advanced information technology, especially for large data analysis, artificial intelligence, can design the 
network monitoring and early warning of financial crime risk model [10].

\section{Design Principles of Risk Early Warning Model}

(1) A comprehensive and effective data source: the data source is the decision support, so the users complete electronic transaction operation data, including electronic terminal, trading site, transaction flow, counterparty, transaction categories, and transaction amount data. And these data is associated in time, and the content is also coherence.

(2) The early warning method of scientific Justice: early warning model needs to establish scientific and fair evaluation indicators. Use the qualitative and quantitative evaluation methods, to establish early warning mechanism. In the model, we need to fully reflect the indicators of financial risk and quantify the indicators, even if the qualitative indicators to give accurate criteria to ensure that the evaluation results are reasonable.

(3) Early warning model of operational model: the data need to collect must be obtained directly or indirectly. In data analysis, selection of evaluation indicators, mining methods, decision-making rules are also shall easy to operation, and has the maneuverability of risk warning.

\section{EARLY RISK WARNING MODEL OF ELECTRONIC FINANCIAL CRIME}

\section{A. Early Risk Warning Model Framework}

The early warning model of the electronic financial crime risk needs to be built on the basis of the big data. Fig. 1 is the design of large data processing model framework.

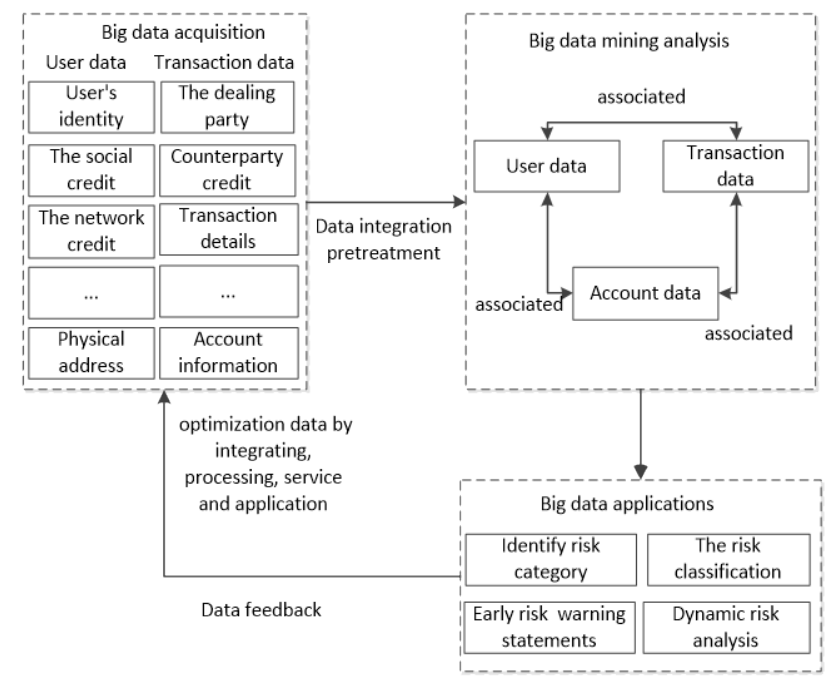

Fig. 1. Erly risk warning mdel famework of big data

(1) Large data collection: firstly, cooperation with the social credit system, electronic financial institutions, obtains relevant data directly through the data interface. Secondly grab the relevant data on the internet by the web crawler system.

(2) Data integration: data integration is a necessary part of data preprocessing for large data mining. According to the factors involved in the electronic financial risk, determine the risk involved in the data, from the massive database of useful data. And these data are converted to make it more suitable for the quantitative treatment of the early warning model, model algorithm requirements and correlation analysis.

(3) Large data mining analysis: data mining analysis is the implementation of electronic financial risk monitoring and early warning system. Big data mining analysis methods include risk index system, statistical model and artificial intelligence.

(4) Data application: Through large data mining can deepen the data application, risk identification, judgment, early warning, monitoring and automatic reporting function.

\section{B. Big Data Mining Analysis Method}

MapReduce is for the big data processing programming model proposed by Google in 2004. It is initially mainly used for large-scale data processing of the Internet. Now it has been applied widely in data mining, data analysis. The Analysis of data in MapReduce platform does not require complex data pretreatment and written to the database, so it can simplify the process of mining. It directly extracts data according to the definition of a given problem from the massive data, and decompose Task according to the data block size of the solution

Fig. 2 is a case to identify the user identity by correlation analysis. On the one hand, the model can begin with the user virtual account information from user information fragments, through the network IP, terminal identification code, website ID and other physical address to identify the true identity of the user information; on the other hand, it can trace from the trading account, and recognize the associated user account information. In the electronic financial, if found suspicious users, suspicious behavior, a cross validation on a user or group identification can from the forward entrance of user and reverse terminal entrance of bank account, and find more related transactions, provide the basis for the electronic financial crime investigation.

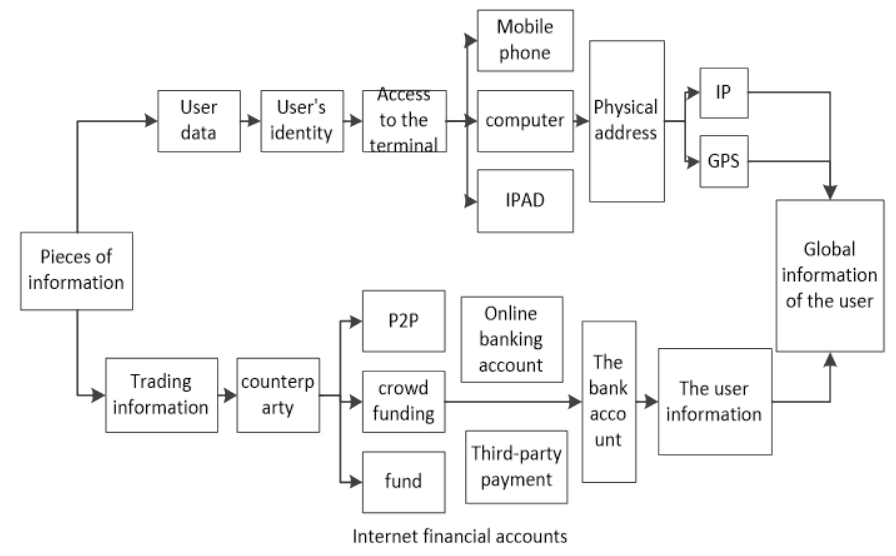

Fig. 2. Example of a correlation analysis 


\section{Early Risk Warning Mechanism}

Risk warning model can be considered to set the following early warning mechanism:

(1) Set the trading limit of the electronic account. Set transaction limit is mainly based on the user or the user group identity information. Especially there is a difficulty to identify the true user, and trading characteristics. set the transaction threshold, and the warning signal is issued if exceeds a threshold.

(2) According to the customer or customer group information characteristics, establish customer risk classification method, in order to achieve effective prevention and control of risk, it should to limit the customer's level of payment limit, monitor the flow of funds and information flow.

(3) To establish and improve the electronic financial internal risk control system, focus on suspicious accounts in real-time, and submit a suspicious transaction report timely.

\section{CONCLUSIONS}

With the rapid development of electronic finance in our country, the problem of electronic financial crime is becoming more and more obvious. The electronic financial personnel involved in a wide range, a high amount, a professional subject of crime with intelligent, strong sense of anti-detection, and electronic evidence of the crime and other characteristics. It needs to use big data technology investigation to establish a risk early warning model for effective monitoring and identification of electronic transactions. Networking warning system will connect to social credit, finance and other departments, and get huge amounts of data. Set parameters and standard according to the electronic transaction feature timely to identify the automatic monitoring of suspicious transactions, realize the intelligent analysis of related data, and issued a warning signal. As for the financial risk prevention and control of the network, it is necessary for the community to cooperate with each other. So it is necessary to adhere to the principle of "risk based public participation". The government encourages the electronic financial innovation also should pay attention to risk prevention at the same time, and guide the healthy development of Internet finance.

\section{REFERENCES}

[1] Berger, Sven C., and F. Gleisner. "Emergence of Financial Intermediaries in Electronic Markets: The Case of Online P2P Lending." Business Research 2.1(2009):39-65.

[2] Werle, Nick. "A microeconomic model of opportunistic financial crimes: prosecutorial strategy when firms are too big to jail." Procedia Economics \& Finance 28(2015):76-84.

[3] Merlonghi, Giorgio. "Fighting financial crime in the age of electronic money: opportunities and limitations." Journal of Money Laundering Control 13.3(2010):202-214.

[4] Odeh, Layan Mazen. "State of Global Financial Crime In--depth Analysis on GCC Countries." British University in Dubai (2012).

[5] Al - Rashdan, Mohammad. "An analytical study of the financial intelligence units' enforcement mechanisms." Journal of Money Laundering Control15.4(2012):483-495.

[6] Wang Zhen-shan,Shi Da-lin. Institutional Investors, Financial Flexibility and Corporate Risk-Taking : Based on the Empirical Research of Dynamic Panel System GMM model. , 2014, 1(09): 64

[7] Chaikin, David A. "Risk-Based Approaches to Combating Financial Crime." Social Science Electronic Publishing (2010):1417-1422.

[8] Kim, Ae Chan, et al. "Fraud and financial crime detection model using malware forensics." Multimedia Tools and Applications 68.2(2014):479496.

[9] Shen, Yu. "Study on Internet Financial Risk Early Warning Based on Big Data Analysis." International Conference on Intelligent Systems Research and Mechatronics Engineering 2015.

[10] Nardo, Massimo. "Building synergies between theory and practice: Countering financial crime on a systemic approach." Journal of Financial Crime 13.3(2006):292-299. 